\title{
HEARING EQUIPMENT
}

The RNID's information development officer describes the products available.

\section{USEFUL INFORMATION}

The Royal National
Institute for Deaf People
105 Gower Street
London WC1E 6AH
Tel: 01713878033
(voice)
01713833154
(Minicom)

$\mathbf{T}$ here are a number of everyday situations, at home and at work, that can present difficulties to a hard of hearing person.

An additional piece of equipment may be all that is required to help them overcome the problem.

The term assistive listening device (ALD) describes equipment which has been designed for or may be used by a deaf or hard of hearing person to enable them to cope more easily with everyday situations.

Here are some common problem areas and possible solutions. Turn to 'Practical advice: Hearing' (page 20) for information on hearing aids.

\section{TELEPHONE USE}

Hearing the 'phone ring can be made easier by means of amplifiers, extension bells and, for the profoundly deaf, flashing lights .

To help partially hearing people hear better when they are on the 'phone, amplifiers and inductive couplers are available. Both can be portable or built into the handset, but inductive couplers are only suitable for people using hearing aids with a 'T' switch.

Keyboard communication, for people with no usable hearing, is offered by facsimile machines, Textphones such as Minicom, and the Typetalk relay system.

\section{TELEVISION VIEWING}

The volume of the television, radio or music player can often be unacceptably loud to other people.

A variety of listening devices can solve this problem, including amplified headsets, loop systems and plug-in listening aids.

\section{ALARM CLOCKS}

Special alarm clocks, fitted with a flashing light and/or vibrating pad, are available. There are also sound activated baby alarms that flash and/or vibrate.

\section{DOOR BELLS}

Louder bells or extension bells can be fitted. There are also visual and vibrating indicators that tell that the door bell is ringing.

\section{FIRE ALARMS}

Conventional fire alarms can be adapted to give a visual or vibrating signal. Smoke detectors with a vibrating pad are also available.

\section{TO OBTAIN THE EQUIPMENT At home}

It is the responsibility of local social services departments (usually the social worker for the deaf or special needs department) to provide equipment for home use.

The address can be found in the telephone directory or from the public library. The availability of devices will vary according to local policies and budget constraints.

It is possible to purchase any ALD from a wide range of suppliers. Information on equipment and suppliers is available from the Royal National Institute for Deaf People.

\section{At work}

Any ALDs required for work must be provided by the user, but they can be obtained from the disablement employment adviser, through the placing, assessment and counselling team direct or through local job centres. Telephone directories have details. 